http://jmscr.igmpublication.org/home/ ISSN (e)-2347-176x ISSN (p) 2455-0450

crossref DOI: https://dx.doi.org/10.18535/jmscr/v7i12.60

\author{
Journal Of Medical Science And Clinical Research \\ IGM Publication \\ An Official Publication of IGM Publication
}

\title{
Five Years Physiotherapy Follow up Post VP Shunt
}

\section{Authors \\ Dr S.S. Subramanian, M.P.T (Orthopaedics), M.S (Education), M. Phil (Education), Ph.D (Physiotherapy)}

The Principal, Sree Balaji College of physiotherapy, Chennai - 100

Affiliated To (Bharath) University, BIHER

Chennai - 73

\begin{abstract}
Non progressive hydrocephalus $(\mathrm{NPH})$ and its treatment using ventriculo peritoneal (VP) shunt among elderly adults were not common. Paucity of researches on post VP shunt with regard to physiotherapy and due follow-up, hence this research gets more significant, where 5 year follow up on 76 year old female with NPH who was treated with VP (Ventriculoperitoneal) shunt and on syndopa, weekly twice frequency for physiotherapy. With her problems such as gait, bladder incontinence, ADL, fear of falling. Clinical prognosis and results were analyzed with evidence.

Keywords: NPH - Non Progressive Hydrocephalus, VP - Ventriculoperitoneal,

$A D L$ - Activities of Daily Living, CSF - Cerebrospinal Fluid.
\end{abstract}

\section{Introduction}

VP (Ventriculoperitoneal) shunt is a medical device that relieves pressure on the brain caused by fluid accumulation, helps to drain the extra CSF (Cerebrospinal Fluid) from the brain, it works by taking the fluid out of the brain and moving it in to the abdomen, where it is absorbed by the body. It is done under general anesthesia and the procedure takes 90 minutes (Erica Roth Falck et al 2017).

VP shunt is a surgical procedure that primarily treats hydrocephalus and is more likely to occur in babies and older adults (Mayo Clinic)

Symptoms of HC (Hydrocephalus) can include head ache, seizures, irritability, incontinence, memory loss, poor coordination, impaired vision, excessive sleeping, poor apetite and cognitive delays. Ultra sound, CT scans, NMRI allow neuro experts to view the cavities and tissues within the brain. Post operative recovery takes 3-4 days and patient gets discharged by $7^{\text {th }}$ day. Risks of VP shunt includes infection in the shunt, bleeding in the brain, blood clot, damage to the brain tissue, swelling of the brain. Fever, head ache, abdominal pain, fatigue and a spike blood pressure levels may indicate mal functioning or infection, which requires medical attention (University of Chicago).

Complications such as mechanical failure, obstructions, infections, over or under draining of CSF. Life span of VP shunt in infant is two years, adults and children may not need a shunt replacement for 8 or more years but requires monitoring and follow up Hydrocephalus (HC Association) 
(Chester Centre for clinical neuro sciences) have stated the aims of physiotherapy post VP shunt are to achieve balance, coordination, improve quality of life, ADL, gait training. With few researches available on physiotherapy post VP shunt and evidenced study of the role of specific physiotherapy this 5 years of longitudinal study gets more significant

Aims \& Objectives of this 5 years research follow up on post VP shunt and movement disorder subject was to evaluate in the role of physiotherapy based on subjects problem and due clinical prognosis.

\section{Background Information}

Mrs.XXX, Aged 81 years, with hypertension

- T10 - L2 Pedicle screw fixation - August 2011

- NPH operated in February 2014, with verticulo peritoneal shunt on Syndopa, Thyronorm and geba pentin since 2013 November,

\section{O/ b}

- Upper throcic kyphosis

- Ambulant unaided but hips lateral rotated and decreased cadence

\section{C/O}

- Pain over lower extremity joints, heaviness of limbs, fear of fall

$\mathbf{O} / \mathbf{E}$

- (Left) hypertonicity, hyperreflexia upper and lower extremities

- Romberg's sign positive

- Ambulant unaided in closed, environment and even surface but needs mild support in uneven and open environments

- Mesomorph

- Bed mobility and transfers independent

- Fear of fall persists - had 2-3 falls each year with no major injuries recorded

- Balance in standing $\rightarrow$ moderate

- Moderate exercise tolerance

- Peripheral joints - full except hip abduction, extension painful and mild restricted
- Motor power both upper and lower extremities $4 / 5$

- ADL - Independent moderatly

Problem List: Dyskinesia, Decreased balance, bladder incontinence, pain and fear of falling

\section{Materials \& Methodology}

$>$ This research subject an octogenarian having undergone ventriculo peritoneal shunt - 2014 and pedicle fixation of T12-L2 vertebra 2011 was treated with specific physiotherapy based on evaluation and her needs in Chennai during the period from March 2014 till September 2019

$>$ Shoulder bracing, neck exercises with moderate resistance in sitting

$>$ Veerasana and modified kattichakrasana for posture correction of kyphosis

$>$ Keagles exercises in supine and high sitting

$>$ Balance training in standing, sideways, reverse walking, making $360^{\circ}$ circle with mild support

$>$ Core strengthening exercises in sitting, supine and side lying postures using an inflatable ball

$>$ Proprioceptive exercises in high sitting and supine positions

> Home programme with regular walking for 15-20 minutes with monitoring to prevent falls With a weekly frequency of twice and each session lasting to 25-30 minutes at an intensity of $60-70 \%$ of her maximal heart rate

\section{Clinical Prognosis and Results}

$>$ Cognitively moderate, impaired bed mobility, movements of peripheral joints are though full with mild extreme ranges restrictions, dyskinesia is marked. With core strengthening exercises using physioball and inversion therapy weekly twice frequency she has made moderate improvements in terms of cadence, peripheral joint pain and posture.

$>$ Balance training in standing, side walking, reverse walking making $360^{\circ}$ circle, helps to overcome fear to falling along with few Proprioceptive exercises 
Inversion postures were used which may help in functioning of VP shunt

Marginal improvement in ADL were recorder

$>$ Slight improvement of bladder continence was recorded in this 5 year follow up.
This 5 year follow up post VP shunt using medications and regular rehabilitation QOL of this subject was sustained and improved in terms of ADL, ambulation, balance, incontinence

\section{Results Table 1}

\begin{tabular}{|l|c|c|c|c|}
\hline $\begin{array}{l}\text { Scale / Score / } \\
\text { Parameter }\end{array}$ & $\begin{array}{c}\text { Berthels } \\
\text { Index }\end{array}$ & Cadence & $\begin{array}{c}\text { Balance (Self } \\
\text { Efficacy Scale) }\end{array}$ & $\begin{array}{c}\text { Revised Urinary } \\
\text { Incontinence Scale }\end{array}$ \\
\hline Pre & 16 & 25 & 47 & 17 \\
\hline Post & 12 & 40 & 32 & 11 \\
\hline
\end{tabular}

\section{Critical Research Questions Arising from this Presentation with Evidence}

1. What physiotherapy post VP shunt can be done to improve QOL?

2. Problem specific exercises for balance, gait, bladder incontinence falls prevention, does it works?

\section{Discussion}

Thompson et al 2017 have among 46 patients diagnosed with NPH were treated with VP shunt, recorded those younger patients had better neurological function and less severe HC appears more to benefit in a 3 month and 1 year follow up using glascowcoma scale and mini mental scale examination post VP shunt rehabilitation measures.

Groh etal 2002 on a 61 year old man with myotonic dystrophy and NPH benefiting post VP shunt in a 10 year follow up with evaluation, treatment and rehabilitation (Yamada et al 2017).

This research subject post VP shunt getting treated for 5 years with specific physiotherapy based on evaluation and her problems, has benefited in response to urinary incontinence, falls prevention, cadence and ADL, as displayed in results table, hence regular follow-up with due adherence to physiotherapy can ensure QOL post VP shunt gets more evidenced

Stolze et al 2000, have recorded improvement in gait as a predictor for responsiveness to shunt, and upper extremity functions in a 88 old male with $\mathrm{NPH}$
Chen etal 2009, among $24 \mathrm{VP}$ and 15 control group, Barthel index improves stresses the importance of early diagnosis and treatment among chronic normal pressure hydrocephalus

Takagi et al 2018, among 18 Japanese patients having normal pressure hydrocephalus treated with CSF diversion procedures have recorded that shunting should be as soon as possible to obtain good surgical results, cognition, incontinence and gait with rehabilitation post shunt surgery

Maramatsu et al 2004 have recorded pleural effusions post VP shunt for normal pressure HC associated with aneurismal subarachnoid heamorage, where as there is no such complications recorded in this subject

As evidenced with above research reports this subject has duly benefited from specific exercises such as regales, Proprioceptive exercises few yoga postures, balance training and core strengthening with regard to incontinence, balance and gait.

\section{Conclusion}

Adherence with proper rehabilitation post VP shunt and associated problems with due follow up can ensure of dignity of the subject and an enhanced quality of life. A major outcome of this follow up research along with physiotherapy, playing a key role.

Limitations of this research was being a case study, and patients problem specific physiotherapy were used 


\section{References}

1. Erica

Roth

Suzanne

Falck.

Ventriculoperitoneal Shunt, 2017 www.healthline.com

2. Thompson SD, Shand Smith JD, Khan AA, Luoma AM, Toma AK, Watkins LD, et al. Shunting of the over 80 s in normal pressure hydrocephalus. Acta Neurochir (Wien) 2017; 159:987-94.

3. Groh W.J., Lowe M.R., Zipes D.P. Severity of cardiac conduction involvement and arrhythmias in myotonic dystrophy type 1 correlates with age and CTG repeat length. J. Cardiovasc. Electrophysiol. 2002;13:444-448.

4. Yamada S, Kimura T, Jingami $N$, et al.: Disability risk or unimproved symptoms following shunt surgery in patients with idiopathic normal-pressure hydrocephalus: post hoc analysis of SINPHONI-2. J Neurosurg. 2017

5. Stolze H, Kuhtz-Buschbeck J, Drucke H, Johnk K, Diercks C, Mehdom HM, Illert M, Deuschl G. Gait analysis in idiopathic normal pressure hydrocephalus-which parameters respond to the CSF tap test? Clin Neurophysol. 2000;111:16781686.

6. Chen Z, Song W, Du J, Li G, Yang Y, Ling F. Rehabilitation of patients with chronic normal-pressure hydrocephalus after aneurysmal subarachnoid hemorrhage benefits from ventriculoperitoneal shunt. Top Stroke Rehabil. 2009 Sep-Oct;16 (5):330-8. doi: 10.1310/tsr1605-330.

7. Takagi Y, Santo K, Hashimoto M, Fukuchi T. Ocular hypotensive effects of prostaglandin analogs in Japanese patients with normal-tension glaucoma: a literature review. Clin Ophthalmol. 2018 Sep 21;12:1837-1844. doi: 10.2147/OPTH.S166657. Collection 2018.
8. Muramatsu H, Koike K. Pleural effusions appearing in the rehabilitation ward after ventriculoperitoneal shunts: a report of two adult cases and a review of the literature. Brain Inj. 2004 Aug;18(8):835-44. 